\title{
UAP56 levels affect viability and mRNA export in Caenorhabditis elegans
}

\author{
MARGARET MACMORRIS, CHAD BROCKER, and THOMAS BLUMENTHAL \\ Department of Biochemistry and Molecular Genetics, University of Colorado School of Medicine, Denver, Colorado 80262, USA
}

\begin{abstract}
Expression of a gfp transgene in the intestines of living Caenorhabditis elegans has been measured following depletion by RNAi of a variety of known splicing factors and mRNA export proteins. Reduction of most splicing factors showed only a small effect on expression of the transgene in the animal injected with dsRNA, although most of these RNAi's resulted in embryonic lethality in their offspring. In contrast, RNAi of nxf-1, the worm homolog of mammalian NXF1/TAP, a key component of the mRNA export machinery, resulted in dramatic suppression of GFP expression in the injected animals. When we tested other proteins previously reported to be involved in marking mRNAs for export, we obtained widely divergent results. Whereas RNAi of the worm REF/Aly homologs had no obvious effect, either in the injected animals or their offspring, RNAi of UAP56, reported to be the partner of REF/Aly, resulted in strong suppression of GFP expression due to nuclear retention of its mRNA. Overexpression of UAP56 also resulted in rapid loss of GFP expression and lethality at all stages of development. We conclude that UAP56 plays a key role in mRNA export in $C$. elegans, but that REF/Aly may not. It also appears that some RNA processing factors are required for viability (e.g., U2AF, PUF60, SRp54, SAP49, PRP8, U1-70K), whereas others are not (e.g., U2A', CstF50).
\end{abstract}

Keywords: RNAi; RNA processing; REF/Aly; exon junction complex (EJC); splicing; helicase

\section{INTRODUCTION}

Processing of pre-mRNA must be completed before mature mRNA is exported from the nucleus. Therefore, blocks in polyadenylation and splicing result in nuclear accumulation of pre-mRNAs (Legrain and Rosbash 1989; Huang and Carmichael 1996a,b). Coupling of splicing and mRNA export may occur through deposition of a complex of proteins called the exon junction complex, or EJC, that marks the mRNA $5^{\prime}$ of the junction between two exons following splicing (Cullen 2000; Kataoka et al. 2000, 2001; Le Hir et al. 2000, 2001a,b; Stutz et al. 2000; Luo et al. 2001; Reichert et al. 2002). One of the EJC proteins, REF/Aly, acts as an adaptor to bind the heterodimer NXF1/TAP:p15/Nxt that catalyzes translocation of the mature mRNA into the cytoplasm (Katahira et al. 1999; Herold et al. 2000; Zhou et al. 2000; Braun et al. 2001). During the process of splicing and transport, some of the proteins present in the EJC are dissociated, and others remain stably bound in the cytoplasm

Reprint requests to: Thomas Blumenthal, Department of Biochemistry and Molecular Genetics, University of Colorado School of Medicine, Box B121, 4200 East 9th Avenue, Denver, CO 80262, USA; e-mail: tom.blumenthal@uchsc.edu; fax: (303) 315-8215.

Article and publication are at http://www.rnajournal.org/cgi/doi/ 10.1261/rna.5480803. and influence translation, mRNA surveillance, and mRNA localization (Le Hir et al. 2001b; Dostie and Dreyfuss 2002). This model for coupling splicing and transport is simple and solves a fundamental problem for the cell, but is it universally true? There are mRNAs, especially in Saccharomyces cerevisiae, that lack introns, yet they exit the nucleus efficiently. In fact it is unclear whether the EJC is required for mRNA transport even in cells where most RNAs have introns. Recent findings indicate that the EJC may play a primary role at a later step in gene expression, translation (Lu and Cullen 2003; Nott et al. 2003). Many of the EJC components and export factors are conserved evolutionarily from S. cerevisiae to humans (Fleckner et al. 1997; Katahira et al. 1999; Stutz et al. 2000), and some evolutionarily distant forms can even be substituted in heterologous cells (Katahira et al. 1999; Strasser and Hurt 2001), indicating that function remains similar and implying conservation of this basic pathway for mRNA export.

A key protein appears to be UAP56, a DExD/H box protein (de la Cruz et al. 1999) required for splicing (Fleckner et al. 1997; Libri et al. 2001). UAP56 was first identified in mammalian cells as a U2AF65-associated factor required for in vitro splicing (Peelman et al. 1995; Fleckner et al. 1997). UAP56 and its well-conserved family members, including Sub2p in yeast, share the usual features of $\mathrm{DExD} / \mathrm{H}$ family 
members, which are presumed ATP-dependent helicases (de la Cruz et al. 1999). Furthermore, although UAP56/ Sub2 clearly functions at an early ATP-independent step in splicing, perhaps to remove U2AF to allow U2 snRNP binding (Kistler and Guthrie 2001; Libri et al. 2001; Zhang and Green 2001), its ATPase activity is nonetheless essential for viability in yeast (Kistler and Guthrie 2001). Therefore, UAP56/Sub2p may have several essential roles, both at an early step of splicing, and at some later step in gene expression.

UAP56 is also important in binding REF/Aly (Linder and Stutz 2001; Luo et al. 2001; Strasser and Hurt 2001) and in recruiting it to the EJC (Jensen et al. 2001). REF/Aly is an RNA-binding protein found from yeast (Yral) to humans (Stutz et al. 2000). It is a component of the EJC (Le Hir et al. 2001b; Reichert et al. 2002), but is also associated with RNAs lacking an EJC (Le Hir et al. 2001b), intronless RNAs (Strasser and Hurt 2001), and with pre-mRNAs soon after transcription (Strasser et al. 2002; Zenklusen et al. 2002), independent of splicing (Kiesler et al. 2002). The association of UAP56 with REF/Aly led to the suggestion that UAP56 plays an essential role in mRNA nuclear export. Blocks to UAP56 function in yeast Sub2 (Strasser and Hurt 2001) or in Drosophila UAP56 (Gatfield et al. 2001) resulted in nuclear accumulation of mRNA. An association between REF/Aly/Yra1 and UAP56/Sub2p, demonstrated both genetically in yeast (Strasser and Hurt 2001) and biochemically in mammalian cells (Luo et al. 2001), provided a mechanism for UAP56 involvement in export. REF/Aly has distinct domains for binding UAP56 and NXF1/TAP, but the REF/Aly-UAP56 interaction on the RNA precedes REF/ Aly binding to NXF1/TAP (Strasser and Hurt 2001). Neither REF/Aly nor NXF1/TAP accompanies the mRNA as it exits the nucleus. These results indicate that REF/Aly acts as an adaptor for mRNA transport. Despite the evolutionary conservation of many of these proteins, the cited sequence of events described above does not hold true in all organisms. REF/Aly is not essential in Drosophila (Gatfield and Izaurralde 2002), implying that it is not the only transport adaptor in that system. Furthermore, some SR proteins can act as transport adaptors (Huang and Steitz 2001; Huang et al. 2003). In fact, it remains possible that the essential role for UAP56 in transport may not be recruitment of transport adaptors.

In Caenorhabditis elegans, the genome encodes homologs to the major proteins involved in splicing, export, and the EJC. The worm UAP56 gene (hel-1) is 75\% identical to its human homolog (Fleckner et al. 1997). C. elegans has two genes encoding NXF1/TAP homologs, $n x f-1$ and $n x f-2$, but only $n x f-1$ is an NXF1/TAP ortholog (Herold et al. 2000; Tan et al. 2000). There are three REF/Aly genes (Stutz et al. 2000), now designated aly-1, aly-2, aly-3 (Longman et al. 2003), and there are other conserved members of the EJC present in C. elegans (SRm160, Y14, and RNPS1 [Longman et al. 2003] and Mago [Li et al. 2000]). Here, we use RNAi
(Fire et al. 1998) to reduce the levels of RNA processing and mRNA transport proteins, as well as some putative components of the EJC, in order to probe their functional significance in worms. Among the essential factors tested, UAP56 is unique in its profile of effects. We extend that result with in vivo studies in which UAP56 is overexpressed, resulting in lethality. Finally, we demonstrate that some putative components of the EJC including REF/Aly are not essential. Our results support the conclusion that UAP56 plays an important role in mRNA export in C. elegans, but one that may not involve REF/Aly.

\section{RESULTS}

\section{Targeting of splicing and export factors by RNAi}

To monitor gene expression following RNAi-induced knock-down of splicing and export factors, we constructed a $g f p$ reporter, pNvitgfp, that is abundantly expressed in the intestinal cells of adult hermaphrodite worms (Fig. 1). Following RNAi, we looked for lowered levels of GFP expression. In all experiments, the treated worms and age-paired controls were scored blindly for GFP levels. Transgenic worms express GFP abundantly, and the GFP is localized in the intestines (Fig. 1B). Most of the GFP is nuclear, owing to the inclusion of a nuclear localization signal (NLS) in the construct.

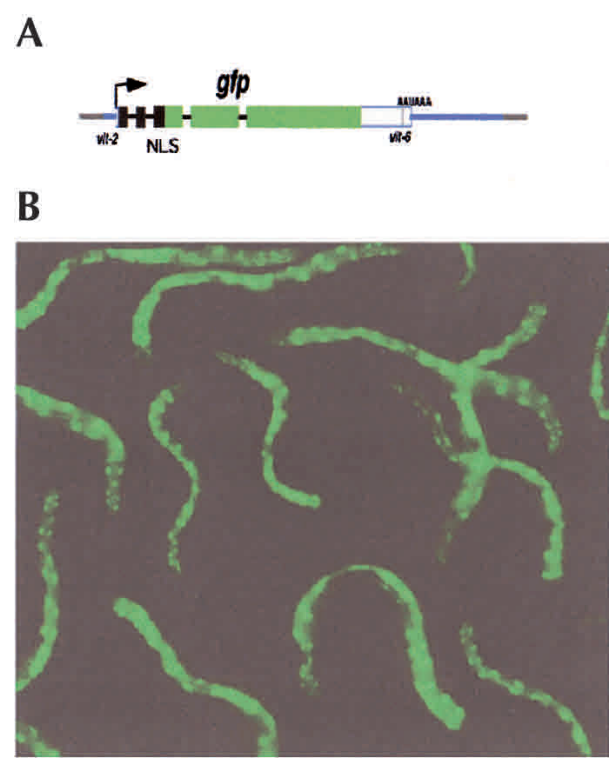

FIGURE 1. Transgenic worms with the integrated pNvitgfp construct express GFP in adult hermaphrodite intestines. (A) For the construct, $247 \mathrm{bp}$ of the vit-2 $5^{\prime}$-flanking region (blue) is fused to vector sequences derived from pPD95.70 (black) that contain two synthetic introns that precede the $g f p$ gene (green). The presence of an NLS directs the GFP to the nucleus. Part of the last exon of vit- 6 provides the 3 '-end formation site (unfilled box). This construct was injected into worms, and a transgenic strain, BL3466, was selected that carries multiple tandem copies of this construct integrated into the genome. (B) GFP expression in BL3466. 
In most cases, we lacked antibodies to demonstrate that the RNAi treatments were effective at lowering the levels of the targeted proteins. However, in three cases we were able to evaluate how much residual protein remained in the injected animals. In the case of U2AF, we previously reported results using an antibody generated against C. elegans U2AF65 (Zorio et al. 1997), and we generated new antibodies against C. elegans UAP56 and PUF60. Antibodies for U2AF65 and UAP56 bound proteins of the appropriate size and did not cross-react significantly with other C. elegans proteins (Fig. 2A). The anti-peptide antibody generated for PUF60 reproducibly reacted with a single protein of $\sim 55 \mathrm{kD}$, a size different from the two predicted products of that gene. We never detected the $81-\mathrm{kD}$ predicted protein with this antibody despite attempts to separate and transfer larger proteins more efficiently. RNAi of each of these genes resulted in clear reductions of their protein products (Fig. 2B). In each case, the loss of predominantly nuclear staining is more marked in embryos and gonadal tissue. In no case did we see levels of staining drop when RNAi was performed against one of the other proteins, confirming the specificity of our antibodies and the RNAi treatments (data not shown).

Expression of the pNvitgfp transgene was measured following RNAi of a variety of genes. Expression was evaluated in each injected worm, placing it in one of five categories ranging from high expression to no expression (OFF; Fig. 3 ). The fraction in each category is shown by the size of the circle, with dark circles representing high expression levels and unfilled circles representing no expression. Expres-
A

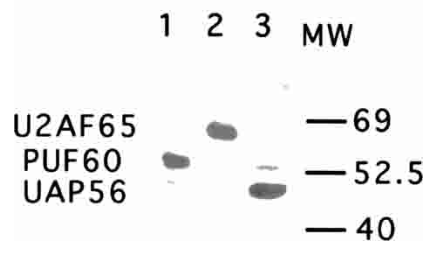

B

RNAi
U2AF
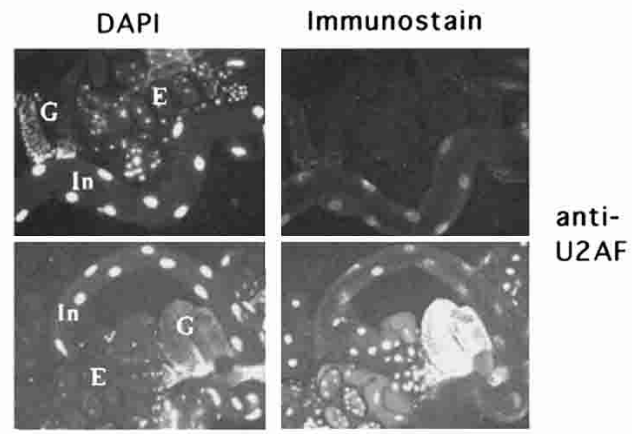

Control
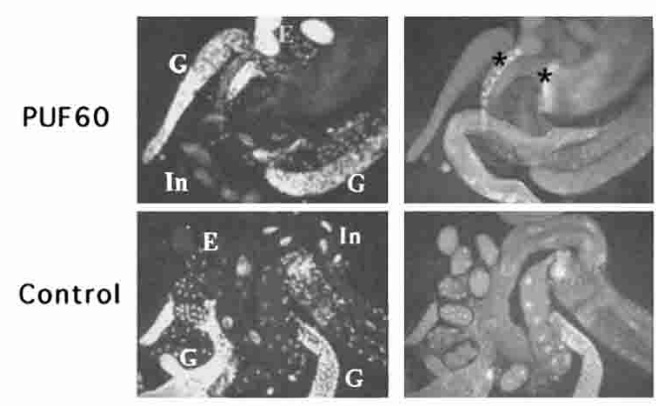

anti-

PUF60
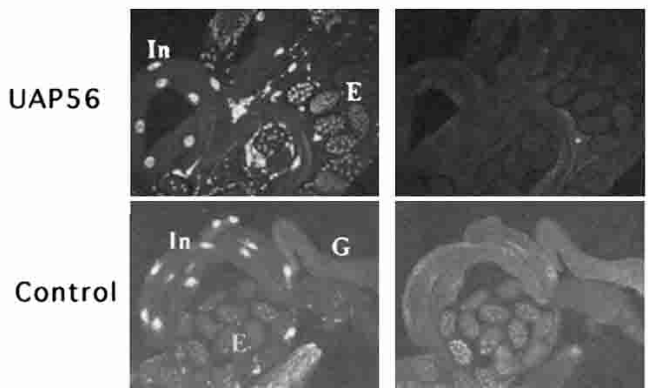

anti-

UAP 56

FIGURE 2. RNAi of UAP56, PUF60, and U2AF65 effectively reduces protein levels. (A) Western blot showing the specificity of the three antibodies. In each panel, the same amount of embryonic extract was electrophoresed, and the blotted protein was reacted with a single antibody: (1) anti-PUF60, (2) anti-U2AF65, or (3) anti-UAP56. (B) Animals were injected with dsRNA of U2AF65, PUF60, or UAP56. The control specimens were uninjected age-paired worms from the pool of animals used for injection. Worms were immunostained with antibodies to the proteins that were subjected to RNAi. Paired DAPI-staining (nuclei) images are shown for each specimen. Large DAPI-staining nuclei characterize intestinal cells (In). Gonads (G) have many close-packed nuclei, and oocytes and embryos (E) have distinct nuclei. Staining for each of the antibodies is predominantly nuclear. One specimen (RNAi of PUF60) has bright artifactual staining $\left(^{\star}\right.$ ) that is extracellular staining of the spermatheca and the edge of the cuticle. 


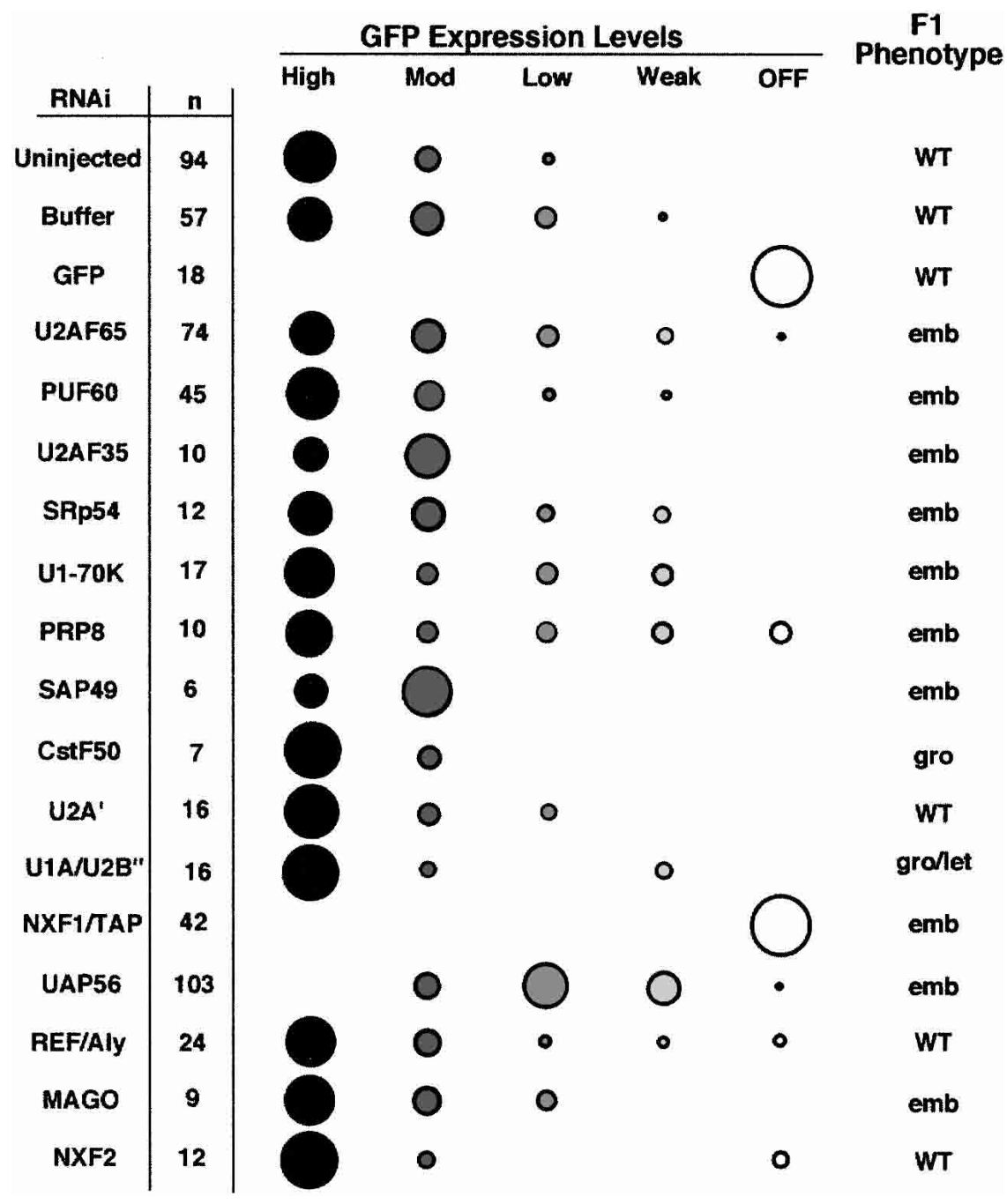

FIGURE 3. Effect of RNAi of RNA processing and mRNA export proteins. RNAi was performed by injection of dsRNA homologous to the genes encoding proteins listed on the left. $\mathrm{U} 1 \mathrm{~A} / \mathrm{U} 2 \mathrm{~B}^{\prime \prime}$ indicates RNAi of both $r n p-2$ and $r n p-3$ together. REF/Aly indicates simultaneous RNAi of the three genes: aly-1, aly-2, and aly-3. The number $(n)$ of injected worms for each RNAi is shown in the second column. Each animal was scored for the level of GFP expression on day 3 and placed in one of the five categories shown in the next three columns. The fraction of animals in each category is reflected by the sizes of the circles. The darkness of the circles is a rough representation of the intensity of GFP in that category. Phenotypes of the offspring of the injected worms are given in the column on the right. (WT) Wild type; (emb) embryonic lethal; (gro) growth defect; (let) lethal.

sion in untreated controls was almost uniformly high, although some individuals had small reductions. Controls injected with buffer showed slightly reduced expression, presumably caused by trauma resulting from the injection procedure. Injection of dsRNA homologous to the $g f p$ gene eliminated all GFP within $1 \mathrm{~d}$. Because in all experiments, worms were scored on the third day after injections, the results should not be due to pools of stable GFP that is resistant to RNA interference. However, it is always possible that the targeted proteins may have stable or abundant pools that make them resistant to the effects of RNAi.

\section{RNAi of RNA processing factors}

We first performed RNAi against C. elegans homologs of several well-characterized RNA processing factors (Fig. 3). The injected animals were monitored for GFP expression, and the survival of their $F_{1}$ progeny was assessed to establish the effectiveness of the dsRNA treatment. When levels of U2AF65, an essential splicing factor (Zorio and Blumenthal 1999), were lowered, GFP expression was reduced only slightly (if at all). Similar results were obtained when other splicing factors, including U2AF35 (Zorio and Blumenthal 1999), U1-70K (Urlaub et al. 2000), PRP8 (Collins and Guthrie 1999), SAP49 (Champion-Arnaud and Reed 1994), and the two members of the PUF complex, PUF60 (Page-McCaw et al. 1999) and SRp54 (Zhang and Wu 1996; Kennedy et al. 1998), were reduced by RNAi. In all of these cases, embryonic lethality was observed in the $F_{1}$ progeny, indicating that the RNAi was indeed effective at lowering levels of the splicing proteins. We note that these results agree with the results reported from genome-wide screens by RNAi, with the exception of PUF60 (Kamath et al. 2003), where lethality was not observed. We interpret these results to mean that sufficient splicing can still take place with lowered levels of these splicing factors to allow transgene expression, but development is much more sensitive to levels of splicing.

RNAi injections of some RNA processing factors did not result in lethality. Whereas RNAi of two subunits of the 3' end cleavage stimulation factor (Takagaki and Manley 1997), CstF-64 and CstF-77, resulted in embryonic lethality (data not shown), RNAi of CstF-50 produced only a developmental delay (slow larval growth) in the progeny. Furthermore, RNAi of the U2 snRNP-specific protein U2A' showed no phenotype at all. When both of the C. elegans homologs of the U1A/U2B"-snRNP-specific proteins were reduced simultaneously, we found only a relatively low level of lethality, along with some developmental delays among the progeny. These nonlethal RNAi's also did not affect the levels of GFP significantly. In these cases, we do not know whether the RNAi failed to lower levels of the targeted protein sufficiently to obtain a phenotype, or whether these proteins do not perform essential functions in C. elegans. 


\section{RNAi of mRNA export and exon junction complex proteins}

In contrast to the results with RNA processing factors, we found that RNAi of the essential RNA transport protein NXF1/TAP resulted in complete elimination of GFP in the injected animals (Fig. 3) and embryonic lethality of their progeny as reported previously (Tan et al. 2000). The response was not as rapid as with RNAi of $g f p$ itself, but GFP was completely gone after $3 \mathrm{~d}$. Evidently, lowering levels of NXF1/TAP is sufficient to rapidly eliminate gene expression. Perhaps it is not surprising that we see a much more rapid and robust effect when we interfere with nuclear export than when we interfere with splicing.

We next tested UAP56, a protein reported to have roles in both splicing and nuclear export of mRNAs. RNAi of UAP56 resulted in reductions in GFP levels that were much greater than those seen when splicing factors were targeted, but the effect was not as great as when NXF1 was reduced (Fig. 3). The result from RNAi of UAP56 was repeated many times in independent blind-scored experiments, and was unique among the many factors we targeted. RNAi of UAP56 always resulted in substantial loss of GFP expression, but it was never as great as when mRNA transport was blocked by RNAi of NXF1/TAP, or when GFP was removed by RNAi of $g f p$ itself. These results indicate that UAP56 does, indeed, play a role in export in C. elegans, but that role may not be as essential to export as that played by NXF1/ TAP.

Recent results from several labs have shown the presence of REF/Aly as a component of the exon junction complex (EJC; Le Hir et al. 2001b; Reichert et al. 2002) and a role for UAP56 in facilitating this association (Jensen et al. 2001). C. elegans has three homologs of REF/Aly (Stutz et al. 2000), all of which appear equally likely to serve a cognate role in mRNA transport. We targeted all three REF/Aly homologs simultaneously, but detected little effect from these treatments, either in lethal or developmental effects to the progeny or in the levels of GFP expression in the injected worms (Fig. 3), similar to the results in the accompanying article (Longman et al. 2003). We also targeted another component of the EJC, Mago. In that case we confirmed the earlier result that mag- 1 is an essential gene required for embryonic survival (Li et al. 2000), but again saw no effect on GFP expression in the injected worms. RNAi to $n x f-2$, a gene with some similarity to $n x f-1$ (Tan et al. 2000), also had no effect, either on development of progeny or on the level of GFP in injected worms.

\section{RNAi of UAP56 causes retention of mRNA in the nucleus}

The GFP phenotype in the RNAi-treated worms is consistent with a role for UAP56 in mRNA transport. To ask directly if we had blocked transport of the $g f p$ mRNA by
RNAi of UAP56, we performed in situ hybridization with a probe that recognizes the $g f p$ mRNA. We hybridized the probe to animals that had been injected with UAP56 dsRNA or other control RNAs. The hybridized specimens were scored for the extent to which each worm intestine (the only tissue in which GFP was expressed) exhibited nuclear localization of the hybridized probe. Control specimens and those injected with dsRNA for splicing factors PUF60 or U2AF65 did not show nuclear localization: they had at most some slight localization of probe in the area of nuclei in a few specimens (Fig. 4a; data not shown). Although we expected RNAi of $n x f-1$ to provide a positive control showing nuclear localization, specimens in which $n x f-1$ was targeted showed so much tissue degeneration that evaluating nuclear localization of the probe was impossible (data not shown). Those specimens treated with UAP56 dsRNA had a majority of the specimens ( 9 of 12 in two experiments) exhibiting strong nuclear localization (Fig. 4c). We conclude that UAP56/hel-1 plays a role in mRNA transport to the cytoplasm in C. elegans.

\section{Lethality caused by overexpression of UAP56}

Overexpression of the UAP56 homolog, Sub2, in yeast has been reported to cause blocks in mRNA export (Strasser and Hurt 2001). To assess the effects of increased levels of UAP56 in worms, we cloned UAP56 under control of the HSP16-41 promoter and created transgenic worms with inducible expression of the UAP56 construct. Heat induction of the UAP56 construct resulted in strong overexpression of UAP56 as shown in Figure 5, A and B. The Western blot (Fig. 5A) indicates that the level of UAP56 is increased 5- to 10 -fold in the transgenic worms. Immunostained individuals (Fig. 5B) demonstrate that the overexpressed protein is

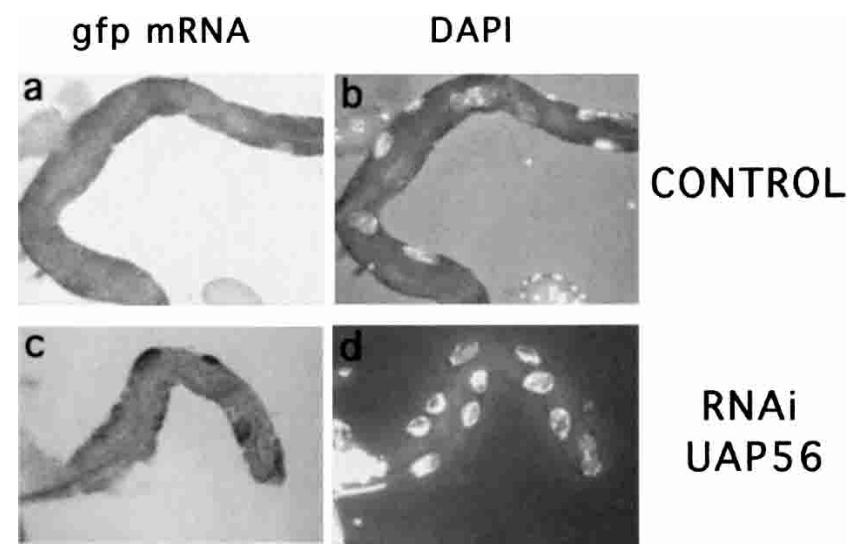

FIGURE 4. RNAi of UAP56 interferes with mRNA transport. In situ hybridization was performed with antisense probe for $g f p$ mRNA on tissues from worms that had been subjected to UAP56 RNAi $(c)$ or uninjected controls $(a) .(b, d)$ DAPI-stained nuclei of the same specimens. Note that in panel $a$, the dark-staining patches do not match the position of nuclei, whereas in panel $c$ they do. 


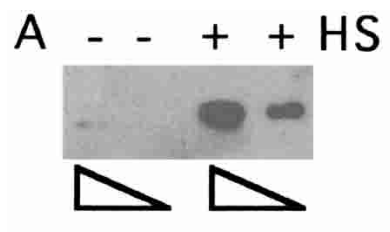

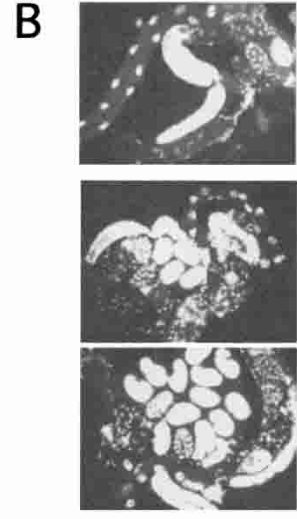

DAPI

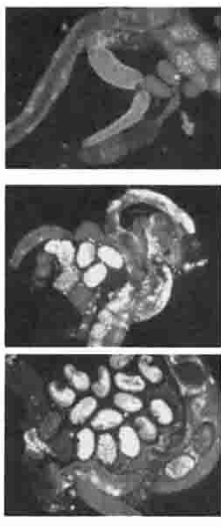

anti-
WT

BL7040

$+\mathrm{HS}$

UAP56

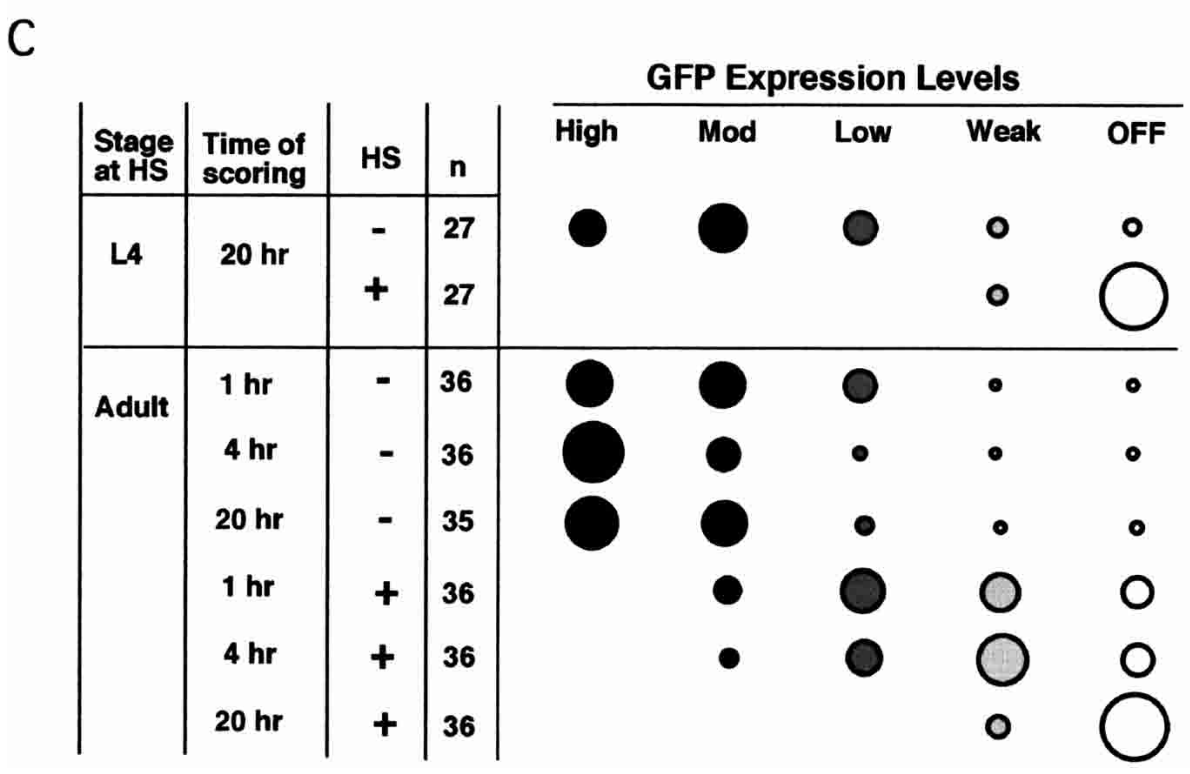

FIGURE 5. Overexpression of UAP56 reduces GFP expression. (A) Western blot showing overexpression of UAP56 following heat shock in BL7040 transgenic worms. Equivalent numbers of worms of the same stage were prepared for the heat-shocked and non-heat-shocked samples $2 \mathrm{~h}$ after heat shock. (B) Heat-shock-induced UAP56 expression is abundant in embryos and intestine. Immunofluorescent staining of wild-type (WT) and heat-shocked BL7040 worms reacted with anti-UAP56 antibody. (C) BL7042 worms transgenic for HS:UAP56 and for vit:gfp were heat-shocked at the L4 larval stage or as young adults. L4 heat-shocked and control worms were scored $20 \mathrm{~h}$ after the heat shock (as adults) for GFP expression. A separate population of worms was heat-shocked as young adults and scored at intervals (1, 4, and $20 \mathrm{~h}$ after heat shock). For each population of size $n$, the percent of animals scored at each level of expression is indicated by the size of the circles as in Figure 3 .

abundant in embryos and in intestine as well as other tissues, and at least some of it appears to be localized in nuclei. Perturbing the normal level of UAP56 at each of the tested stages of development resulted in lethality and developmental arrest (Table 1). At embryonic and early larval stages, development appeared to arrest immediately, although the animals survived and retained some locomotion for up to a day before dying. At later stages, like L4 larvae, the next generation was also affected. L4 animals molted to become adults after heat shock but did not appear gravid and had no progeny. They looked very small for adults, had limited mobility, and died within a few days. When animals were heat-shocked as young adults, before they had begun laying eggs, they appeared healthy after the heat shock and moved extensively although somewhat uncoordinatedly for $2-3 \mathrm{~d}$ at least. However, they were thin compared with their control counterparts and they had reduced fertility with only a few progeny per worm (Table 1). In contrast, overexpression of the essential splicing factors U2AF65 and U2AF35 does not produce any visible effect on worm development (D.A. Zorio and T. Blumenthal, unpubl.).

We monitored the effects of excess expression of UAP56 in a situation similar to the assay shown in Figure 3 by crossing the inducible UAP56 construct into the transgenic 
TABLE 1. Overexpression of UAP56 arrests development and interferes with fertility

\begin{tabular}{|c|c|c|c|c|}
\hline & $\mathrm{n}$ & $\%$ Survival & Phenotype & Fertility \\
\hline \multicolumn{5}{|c|}{ N2 heat shocked } \\
\hline Embryo & 645 & 98 & WT & \\
\hline L1 & 956 & 100 & WT & \\
\hline L2-L3 & 160 & 100 & WT & \\
\hline L4 & 53 & 100 & WT & 87 \\
\hline Adult & 200 & NA & WT & 68 \\
\hline \multicolumn{5}{|c|}{ BL7040 control NO HS } \\
\hline Embryo & 641 & 98 & WT & \\
\hline L1 & 643 & 100 & WT & \\
\hline L2-L3 & 167 & 100 & WT & \\
\hline L4 & 100 & 100 & WT & 117 \\
\hline Adult & 200 & NA & WT & 129 \\
\hline \multicolumn{5}{|c|}{ BL7040 heat shocked } \\
\hline Embryo & 620 & 0 & Emb lethal & \\
\hline L1 & 600 & 0 & Larval lethal & \\
\hline L2-L3 & 163 & 0 & Larval lethal & \\
\hline L4 & 100 & 0 & Sick adults & 0 \\
\hline Adult & 200 & NA & Adults thin, Unc & 3 \\
\hline \multicolumn{5}{|c|}{$\begin{array}{l}\text { Wild-type (N2) and BL7040 worms transgenic for HS:UAP56 were } \\
\text { heat-shocked at several developmental stages and monitored for } \\
\text { survival. Embryos were scored for hatching, and worms heat- } \\
\text { shocked as larvae were assessed for maturation to adult stage and } \\
\text { fertility (number of progeny per worm). } n \text { is the number of worms } \\
\text { scored in each experiment. (NA) Not applicable, (Unc) uncoordi- } \\
\text { nated movement. }\end{array}$} \\
\hline
\end{tabular}

strain expressing pNvitgfp. Stage-matched animals from the strain BL7042, bearing both transgenes, were selected, and half of the worms were heat-shocked. The healthiest worms from each population were selected and individually scored for GFP levels. Because worms heat-shocked as L4 larvae looked very sick by the time they were scored at $20 \mathrm{~h}$ after the heat shock, the lack of GFP expression was not surprising (Fig. 5C). To look at a potentially more specific effect, we selected a very young adult population, subdivided it, and heat-shocked half the population for $2 \mathrm{~h}$, then scored individuals blindly for GFP expression at defined times after the end of the heat shock. By the first scoring at 1-1.5 h, expression was dramatically reduced (Fig. 5C). At this time point, there was little morphological difference between the animals that had experienced the heat shock and those that had not. After $4 \mathrm{~h}$, GFP levels were even more reduced, and by $20 \mathrm{~h}$, GFP was only barely detectable and only in a few animals; it was completely eliminated in most. At this point, the heat-shocked worms were beginning to appear less healthy and distinguishable from the controls, but they were still moving well and all were living. We also heat-shocked the transgenic strain BL3466 carrying only the reporter gene (used for the RNAi experiments in Fig. 3), and showed that heat shock alone does not reduce GFP expression. That strain has slightly more robust GFP expression than the BL7042 doubly transgenic strain, making direct comparisons between the two after heat shock less useful. This could be caused by a small amount of "leaky" UAP56 expression in the absence of a heat shock. We conclude that the $C$. elegans gene for UAP56 has an essential role that is required at all stages in development. The worm is sensitive to the level of this protein; both reduction in its level and overproduction result in lethality. Most likely, the level of UAP56 is crucial for mRNA transport.

\section{DISCUSSION}

\section{UAP56 is an essential protein in $C$. elegans involved in $\mathrm{mRNA}$ export}

We used RNAi to demonstrate that UAP56 is essential for embryonic survival in C. elegans. The same was true for RNAi of other splicing factors (U2AF65, U2AF35, PUF60, SRp54, U1-70K, PRP8, SAP49), all of which we found to be essential for development. However, when levels of GFP were assayed in the injected worms, as an indicator of export of mRNA of the $g f p$ reporter, UAP56 reduction resulted in a profile quite distinct from other splicing factors. If UAP56 were acting only during splicing, we would have expected results similar to those found upon depletion of other splicing factors. The conclusion from the GFP reporter assay that UAP56 may play a role in export was confirmed by in situ hybridization results showing nuclear accumulation of the $g f p$ reporter mRNA after UAP56 reduction. However, RNAi of NXF1/TAP, a required RNA transport factor, reduced GFP levels much more dramatically; thus, it appears that UAP56 may play a different sort of role in export.

\section{RNAi of RNA processing proteins}

We report here for the first time that both PUF60 and SRp54 are essential for C. elegans embryonic development. These two proteins were first reported to be associated with U2AF65 and to form a tight complex in mammalian cells that enhanced U2 snRNP binding (Page-McCaw et al. 1999), but their roles in splicing have not been further elucidated. Our result that PUF60 is essential differs from that obtained in genome-wide RNAi screens in C. elegans (Kamath et al. 2003), but it is not unusual for injected dsRNA to have a more potent RNAi effect than dsRNA introduced by feeding or soaking (data not shown). Among the snRNP-associated proteins, we find that U1-70K is essential and that $\mathrm{U}^{2} \mathrm{~A}^{\prime}$ is not. In Drosophila, $\mathrm{U}_{2} \mathrm{~A}^{\prime}$ is essential (Nagengast and Salz 2001), as is the U1A/U2B" homolog snf (Salz and Flickinger 1996). In contrast, U1A is nonessential in yeast (Tang and Rosbash 1996). In C. elegans, we found reduced viability and developmental defects when both $\mathrm{U} 1 \mathrm{~A} / \mathrm{U} 2 \mathrm{~B}^{\prime \prime}$ gene products were lowered, but no effect with reduction of either alone (data not shown), indicating redundant functions of the two gene products. Differences in the requirements for these individual snRNP-associated 
proteins between systems may reflect real differences in their function. We also found that reduction of the C. elegans CstF-50 subunit by RNAi did not result in loss of viability, whereas RNAi of the other two subunits of CstF did. Mutations in CstF-50 have not been reported in other systems, but the three subunits function together in mammalian cell extracts (Takagaki and Manley 2000).

\section{RNAi of putative EJC components demonstrates they are nonessential for export}

RNAi of the putative components of the EJC, including mag- 1 and the three REF/Aly homologs, does not support the idea that they play an important role in export. The RNAi experiment with mag-1 gave results validating the RNAi efficacy, yet had no effect on GFP levels. We also found no effects when we simultaneously lowered the levels of all three REF/Aly homologs. Of course, RNAi is not always effective in depleting protein levels, especially if there is a stable pool of protein present. This may be the case with some of the apparently nonessential RNA processing factors such as U2A', U1A/U2B", or CstF-50. Alternatively, factors that we have targeted may be redundant in the cell. If an alternative protein performs the necessary function, without having substantial sequence similarity, then we would not have recognized its role. This could be the case with the putative adaptor proteins REF/Aly-1, REF/Aly-2, and REF/ Aly-3. We did not verify the depletion of these proteins because we lacked an antibody, but our result is similar to that found in Drosophila, in which the two REF proteins were dispensable for cell viability and growth and appeared not to be involved in mRNA transport (Gatfield and Izaurralde 2002). Longman et al. (2003) have also independently found that REF/Aly-1, REF/Aly-2, and REF/Aly-3 are not required for mRNA transport in worms.

\section{C. elegans UAP56 may play a role in mRNA transport that does not involve REF}

The putative role for UAP56 in mRNA transport is recruitment of REF/Aly to the EJC. The association between REF/ Aly and UAP56 is likely to be conserved in the worm. The sequence of the REF C-terminal domain responsible for UAP56 interaction (Luo et al. 2001) shows greater conservation between the human and $C$. elegans sequences than between human and yeast (Stutz et al. 2000), and yet yeast REF (Yra1) can be replaced by human REF in binding assays with both Sub2/UAP56 and Mex67/TAP (Strasser and Hurt 2001). Nonetheless, even though in both Drosophila melanogaster (Gatfield et al. 2001) and C. elegans, UAP56 is essential and appears to play a role in mRNA export, its suggested partner linking it to export, REF/Aly, is not required for viability (Gatfield and Izaurralde 2002). This implies that either the essential role for UAP56 in export does not involve recruiting an export adaptor or that another protein plays the adaptor role in flies and worms. One possible adaptor would be Srp20 or 9G8, because these proteins have been suggested to have such a role in mammals (Huang and Steitz 2001; Huang et al. 2003). However, the sole worm gene homologous to these two proteins, rsp-6, is nonessential (Longman et al. 2000), and RNAi of $r s p-6$ does not result in reduction of GFP levels in our reporter strain (data not shown).

In Xenopus oocyte experiments, UAP56 and REF/Aly interact and their levels must be matched for optimal mRNA export. Introduction of excess UAP56 was able to block mRNA export, presumably by binding its partner REF/Aly. Excess introduced REF/Aly was able to counteract the block in export (Luo et al. 2001). The result does not, however, exclude the possibility that other adaptor proteins might also play a role. In C. elegans we have shown that overexpression of UAP56 is lethal to the worms at all stages during development. It also very quickly lowers GFP expression, indicating a block in mRNA export more rapid than that seen by depleting NXF1/TAP by RNAi. It is remarkable that the excess UAP56 abruptly stops development and growth as well as production of progeny, implying that the level of UAP56 in the cell is critical for normal cell function. Because REF/Aly does not seem to be required for export, it seems likely that excess UAP56 stops growth by a different mechanism than demonstrated in the Xenopus experiments.

\section{MATERIALS AND METHODS}

\section{Constructs}

The $g f p$ reporter constructs used previously (MacMorris et al. 1999) were modified to give more robust GFP expression that is localized better to nuclei. The XbaI/BstZ171 fragment from pPM99 (vit: gfp) was replaced by the XbaI/BstZ171 fragment from pCR2 (provided by D. Zarkower, University of Minnesota, Minneapolis [Yi and Zarkower 1999]), a derivative of pPD95.70 [A. Fire, Carnegie Institute of Washington]. The replacement resulted in the addition of three introns in the enhanced $g f p(\mathrm{Q} 80 \mathrm{R}$, S65C) with an N-terminal SV40 T-antigen nuclear localization signal (NLS). The new construct is pNvitgfp (pPM143). UAP56 was cloned for expression in Escherichia coli as a GST fusion protein by ligation of the $\mathrm{Xba} \mathrm{I} / \mathrm{Sac}$ I fragment of the cDNA yk110a2 into pGEX-KG cut with $X b a \mathrm{I}$ and SacI to create pPM155. The HSUAP56 plasmid for expression of UAP56 in worms under heatshock control was made in two steps. Reverse PCR (Coolidge and Patton 1995) of pPD49.83, with primers HSuap56us: ACGAC GATAAGAATTCGCGTCGACGGTACCATGG and HSuap56ds: CATCCTTGTAATCCATCGCTAGCCAAGGGTCCTCC, inserted a Flag sequence and an EcoRI restriction site into pPD49.83 to create pPM159. The EcoRI/ KpnI fragment of cDNA yk110a2 was ligated into EcoRI/KpnI-digested pPM159 to create the plasmid pPM158.

\section{Transgenics and worms}

General procedures for maintaining and handling C. elegans were used (Brenner 1974). Transgenic line BL3460 [inEx749 (pPM143)] 
was made by standard methods without a coinjected plasmid (Mello et al. 1991). The extrachromosomal array was integrated by $\gamma$-irradiation $(3800 \mathrm{R})$ of BL3460 and selection to produce BL3466 [inIs173 (pNvitgfp)] after two outcrosses. BL7040 (inIs177) is an integrated line twice outcrossed, derived from BL7033 [inEx751(pPM158; pTZ1-7.6)], in which pTZ1-7.6 (ida::gfp) (Zahn et al. 2001) was the coinjected marker plasmid. BL7042 (inIs173; inIs177) was derived by crossing BL3466 with BL7040 and selecting worms carrying both vit::gfp and ida::gfp markers. Expression of HSUAP56 in BL7042 was confirmed by Western blots using an antibody against the Flagtagged UAP56.

Synchronized populations of developing worms were prepared for the heat-shock-induced expression of UAP56 by alkaline hypochlorite treatment (Emmons et al. 1979) to isolate embryos. The embryos were allowed to hatch in M9 to produce populations of L1 larvae and later larval stages after feeding. The L2L3 population was produced by allowing isolated embryos to hatch on plates spread with E. coli and develop for $24 \mathrm{~h}$. Embryos for heat shock were prepared by allowing gravid adults to lay eggs for $2 \mathrm{~h}$, then removing all hatched embryos and adults by extensive washing. Heat shocks at $32^{\circ} \mathrm{C}$ for $2 \mathrm{~h}$ were given by floating petri dishes of worms in a controlled-temperature water bath. In all cases, the survival percentages were normalized by the survival of N2 controls. Because 2-h heat shocks produced a high level of lethality with N2 control embryos, embryonic heat shocks were only at $32^{\circ} \mathrm{C}$ for $1 \mathrm{~h}$. Fertility was assessed by allowing adults to deposit embryos for $24 \mathrm{~h}$ and counting the number of progeny $3 \mathrm{~d}$ later.

\section{RNAi}

RNA transcripts were made from cDNA clones (see Table 2) using T7, T3, or SP6 RNA polymerases (Ampliscribe kit, Epicentre). Aliquots of the RNAs were separated electrophoretically to verify size and integrity and to estimate concentration (combined with spectrophotometric estimation of concentration). Equimolar mixtures of the two complementary transcripts for each construct were denatured at $65^{\circ} \mathrm{C}$ and allowed to anneal at $37^{\circ} \mathrm{C}$ for $30 \mathrm{~min}$. The mixture was injected at $\sim 0.4-1 \mathrm{mg} / \mathrm{mL}$. Adult hermaphrodites of BL3466 (pPM143) were injected with RNA and allowed to recover and deposit early embryos (to eliminate untreated embryos) for $\sim 16 \mathrm{~h}$. Progeny produced during 24 -h intervals subsequently were collected and monitored for survival and growth to verify the effectiveness of the RNAi treatment in each individual. Injected animals were each scored blindly at $\sim 48 \mathrm{~h}$ and $\sim 72 \mathrm{~h}$ after injection for GFP expression level using a Leica MZ6 stereomicroscope, equipped with epifluorescence attachments.

\section{In situ hybridization}

BL3466 individuals injected with dsRNA for $n x f-1$, uaf-1, PUF60, or UAP56 were monitored in the usual way for efficacy of RNAi treatment, then used to prepare whole-mount cut worms for hybridization on day 3 after injection. Worms were cut with a 25gauge needle in PBS $(+2.5 \mathrm{mM}$ levamisole) to extrude intestines and gonads on poly-lysine subbed slides. Worm tissue was immediately fixed by adding an equal volume of 5\% paraformaldehyde, with cover slipping and freezing on dry ice. The method for processing slides was essentially according to Evans et al. (1994), and the probe was a digoxigenin-labeled RNA probe complementary to the entire coding region of $g f p$. A sense strand probe was also made for use as a control. Proteinase K treatment was at $20 \mu \mathrm{g} / \mathrm{mL}$. Hybridization was overnight $(\sim 16 \mathrm{~h})$, and anti-digoxigenin antibody incubation was at $4^{\circ} \mathrm{C}$ overnight $(\sim 16 \mathrm{~h})$. After developing slides with NBT/BCIP, and staining with DAPI, images were captured with a Nikon E600 using Scion Image software. In each case, paired control and experimental images were captured equivalently with the same settings and magnification.

\section{Antibody production and immunostaining}

All antibodies were polyclonal rabbit sera. The pGEX-derived plasmid pPM155 containing the GST-UAP56 fusion was transformed into XA90 cells for expression. The induced GST-UAP56 fusion protein was isolated from an SDS-PAGE gel and used to immunize rabbits (Pocono Rabbit Farm and Laboratory). Subsequently, the specificity of the polyclonal antiserum (\#16506) was improved by supplementary injections of purified UAP56, thrombin-cleaved from the GST. Production of the U2AF65 antibody has been described previously (AbRA-18; Zorio et al. 1997). The PUF60 antibody was made to a peptide at the $\mathrm{N}$ terminus of the predicted gene's sequence (EENSADIENRPVAAFRPC). For immunostaining, worms were cut open on subbed slides to extrude tissues and then methanol/acetone-fixed (Strome and Wood 1982). The antibodies used were affinity-purified by binding and elution from nitrocellulose-blotted proteins expressed in E. coli. Antibodies were incubated with fixed specimens at $4^{\circ} \mathrm{C}$ overnight, followed by a FITC-conjugated AffiPure goat anti-rabbit secondary antibody (Jackson Immunoresearch 111-095-144). Polyclonal sera (not affinity-purified) were used for Western blots; standard samples of embryo extracts $(\sim 5 \mu \mathrm{g}$ each) were electrophoresed on $10 \%$ acrylamide SDS-PAGE gels, electrotransferred with a semidry electro- 
transfer apparatus (BioRad) to nitrocellulose, then reacted with the three antibodies to verify specificity.

\section{ACKNOWLEDGMENTS}

We thank Yuji Kohara at the National Institute of Genetics, Japan, and Barbara Felber for providing cDNAs and Dasa Longman and Javier Caceres for communication of results before publication. We thank David Caprio for expert technical assistance. Support was provided by a grant from NIGMS, GM59027.

The publication costs of this article were defrayed in part by payment of page charges. This article must therefore be hereby marked "advertisement" in accordance with 18 USC section 1734 solely to indicate this fact.

Received March 10, 2003; accepted April 14, 2003.

\section{REFERENCES}

Braun, I.C., Herold, A., Rode, M., Conti, E., and Izaurralde, E. 2001. Overexpression of TAP/p 15 heterodimers bypasses nuclear retention and stimulates nuclear mRNA export. J. Biol. Chem. 276: 20536-20543.

Brenner, S. 1974. The genetics of Caenorhabditis elegans. Genetics 77: 71-94.

Champion-Arnaud, P. and Reed, R. 1994. The prespliceosome components SAP 49 and SAP 145 interact in a complex implicated in tethering U2 snRNP to the branch site. Genes \& Dev. 8: 1974-1983.

Collins, C.A. and Guthrie, C. 1999. Allele-specific genetic interactions between Prp8 and RNA active site residues suggest a function for Prp8 at the catalytic core of the spliceosome. Genes \& Dev. 13: $1970-1982$.

Coolidge, C.J. and Patton, J.G. 1995. Run-around PCR: A novel way to create duplications using polymerase chain reaction. Biotechniques 18: $762-764$.

Cullen, B.R. 2000. Connections between the processing and nuclear export of mRNA: Evidence for an export license? Proc. Natl. Acad. Sci. 97: 4-6.

de la Cruz, J., Kressler, D., and Linder, P. 1999. Unwinding RNA in Saccharomyces cerevisiae: DEAD-box proteins and related families. Trends Biochem. Sci. 24: 192-198.

Dostie, J. and Dreyfuss, G. 2002. Translation is required to remove Y14 from mRNAs in the cytoplasm. Curr. Biol. 12: 1060-1067.

Emmons, S.W., Klass, M.R., and Hirsh, D. 1979. Analysis of the constancy of DNA sequences during development and evolution of the nematode Caenorhabditis elegans. Proc. Natl. Acad. Sci. 76: 13331337.

Evans, T.C., Crittenden, S.L., Kodoyianni, V., and Kimble, J. 1994. Translational control of maternal glp-1 mRNA establishes an asymmetry in the C. elegans embryo. Cell 77: 183-194.

Fire, A., Xu, S., Montgomery, M.K., Kostas, S.A., Driver, S.E., and Mello, C.C. 1998. Potent and specific genetic interference by double-stranded RNA in Caenorhabditis elegans. Nature 391: 806811.

Fleckner, J., Zhang, M., Valcarcel, J., and Green, M.R. 1997. U2AF65 recruits a novel human DEAD box protein required for the $\mathrm{U} 2$ snRNP-branchpoint interaction. Genes \& Dev. 11: 1864-1872.

Gatfield, D. and Izaurralde, E. 2002. REF1/Aly and the additional exon junction complex proteins are dispensable for nuclear mRNA export. J. Cell Biol. 159: 579-588.

Gatfield, D., Le Hir, H., Schmitt, C., Braun, I.C., Kocher, T., Wilm, M., and Izaurralde, E. 2001. The DExH/D box protein HEL/UAP56 is essential for mRNA nuclear export in Drosophila. Curr. Biol. 11: 1716-1721.

Herold, A., Suyama, M., Rodrigues, J.P., Braun, I.C., Kutay, U.,
Carmo-Fonseca, M., Bork, P., and Izaurralde, E. 2000. TAP (NXF1) belongs to a multigene family of putative RNA export factors with a conserved modular architecture. Mol. Cell. Biol. 20: 8996-9008.

Huang, Y. and Carmichael, G.C. 1996a. Role of polyadenylation in nucleocytoplasmic transport of mRNA. Mol. Cell. Biol. 16: 15341542.

- 1996b. A suboptimal 5' splice site is a cis-acting determinant of nuclear export of polyomavirus late mRNAs. Mol. Cell. Biol. 16: 6046-6054.

Huang, Y. and Steitz, J.A. 2001. Splicing factors SRp20 and 9G8 promote the nucleocytoplasmic export of mRNA. Mol. Cell 7: 899905.

Huang, Y., Gattoni, R., Stevenin, J., and Steitz, J.A. 2003. SR splicing factors serve as adapter proteins for TAP-dependent mRNA export. Mol. Cell 11: 837-843.

Jensen, T.H., Boulay, J., Rosbash, M., and Libri, D. 2001. The DECD box putative ATPase Sub2p is an early mRNA export factor. Curr. Biol. 11: 1711-1715.

Kamath, R.S., Fraser, A.G., Dong, Y., Poulin, G., Durbin, R., Gotta, M., Kanapin, A., Le Bot, N., Moreno, S., Sohrmann, M., et al. 2003. Systematic functional analysis of the Caenorhabditis elegans genome using RNAi. Nature 421: 231-237.

Katahira, J., Strasser, K., Podtelejnikov, A., Mann, M., Jung, J.U., and Hurt, E. 1999. The Mex67p-mediated nuclear mRNA export pathway is conserved from yeast to human. EMBO J. 18: 2593-2609.

Kataoka, N., Yong, J., Kim, V.N., Velazquez, F., Perkinson, R.A., Wang, F., and Dreyfuss, G. 2000. Pre-mRNA splicing imprints mRNA in the nucleus with a novel RNA-binding protein that persists in the cytoplasm. Mol. Cell 6: 673-682.

Kataoka, N., Diem, M.D., Kim, V.N., Yong, J., and Dreyfuss, G. 2001. Magoh, a human homolog of Drosophila mago nashi protein, is a component of the splicing-dependent exon-exon junction complex. EMBO J. 20: 6424-6433.

Kennedy, C.F., Kramer, A., and Berget, S.M. 1998. A role for SRp54 during intron bridging of small introns with pyrimidine tracts upstream of the branch point. Mol. Cell. Biol. 18: 5425-5434.

Kiesler, E., Miralles, F., and Visa, N. 2002. HEL/UAP56 binds cotranscriptionally to the Balbiani ring pre-mRNA in an intron-independent manner and accompanies the BR mRNP to the nuclear pore. Curr. Biol. 12: 859-862.

Kistler, A.L. and Guthrie, C. 2001. Deletion of MUD2, the yeast homolog of U2AF65, can bypass the requirement for sub2, an essential spliceosomal ATPase. Genes \& Dev. 15: 42-49.

Le Hir, H., Izaurralde, E., Maquat, L.E., and Moore, M.J. 2000. The spliceosome deposits multiple proteins 20-24 nucleotides upstream of mRNA exon-exon junctions. EMBO J. 19: 6860-6869.

Le Hir, H., Gatfield, D., Braun, I.C., Forler, D., and Izaurralde, E. 2001a. The protein Mago provides a link between splicing and mRNA localization. EMBO Rep. 2: 1119-1124.

Le Hir, H., Gatfield, D., Izaurralde, E., and Moore, M.J. 2001b. The exon-exon junction complex provides a binding platform for factors involved in mRNA export and nonsense-mediated mRNA decay. EMBO J. 20: 4987-4997.

Legrain, P. and Rosbash, M. 1989. Some cis- and trans-acting mutants for splicing target pre-mRNA to the cytoplasm. Cell 57: 573-583.

Li, W., Boswell, R., and Wood, W.B. 2000. mag-1, a homolog of Drosophila mago nashi, regulates hermaphrodite germ-line sex determination in Caenorhabditis elegans. Dev. Biol. 218: 172-182.

Libri, D., Graziani, N., Saguez, C., and Boulay, J. 2001. Multiple roles for the yeast SUB2/yUAP56 gene in splicing. Genes \& Dev. 15: 3641.

Linder, P. and Stutz, F. 2001. mRNA export: Travelling with DEAD box proteins. Curr. Biol. 11: R961-R963.

Longman, D., Johnstone, I.L., and Caceres, J.F. 2000. Functional characterization of SR and SR-related genes in Caenorhabditis elegans. EMBO J. 19: 1625-1637.

— 2003. The Ref/Aly proteins are dispensable for mRNA export and development in Caenorhabditis elegans. RNA (this issue). 
Lu, S. and Cullen, B.R. 2003. Analysis of the stimulatory effect of splicing on mRNA production and utilization in mammalian cells. RNA 9: 618-630.

Luo, M.L., Zhou, Z., Magni, K., Christoforides, C., Rappsilber, J., Mann, M., and Reed, R. 2001. Pre-mRNA splicing and mRNA export linked by direct interactions between UAP56 and Aly. $\mathrm{Na}$ ture 413: 644-647.

MacMorris, M.A., Zorio, D.A., and Blumenthal, T. 1999. An exon that prevents transport of a mature mRNA. Proc. Natl. Acad. Sci. 96: 3813-3818.

Mello, C.C., Kramer, J.M., Stinchcomb, D., and Ambros, V. 1991. Efficient gene transfer in C. elegans: Extrachromosomal maintenance and integration of transforming sequences. EMBO J. 10: 3959-3970.

Nagengast, A.A. and Salz, H.K. 2001. The Drosophila U2 snRNP protein $\mathrm{U}^{2} \mathrm{~A}^{\prime}$ has an essential function that is $\mathrm{SNF} / \mathrm{U} 2 \mathrm{~B}^{\prime \prime}$ independent. Nucleic Acids Res. 29: 3841-3847.

Nott, A., Meislin, S.H., and Moore, M.J. 2003. A quantitative analysis of intron effects on mammalian gene expression. RNA 9: 607-617.

Page-McCaw, P.S., Amonlirdviman, K., and Sharp, P.A. 1999. PUF60: A novel U2AF65-related splicing activity. RNA 5: 1548-1560.

Peelman, L.J., Chardon, P., Nunes, M., Renard, C., Geffrotin, C., Vaiman, M., Van Zeveren, A., Coppieters, W., van de Weghe, A., Bouquet, Y., et al. 1995. The BAT1 gene in the MHC encodes an evolutionarily conserved putative nuclear RNA helicase of the DEAD family. Genomics 26: 210-218.

Reichert, V.L., Le Hir, H., Jurica, M.S., and Moore, M.J. 2002. 5' exon interactions within the human spliceosome establish a framework for exon junction complex structure and assembly. Genes \& Dev. 16: $2778-2791$.

Salz, H.K. and Flickinger, T.W. 1996. Both loss-of-function and gainof-function mutations in snf define a role for snRNP proteins in regulating Sex-lethal pre-mRNA splicing in Drosophila development. Genetics 144: 95-108.

Strasser, K. and Hurt, E. 2001. Splicing factor Sub2p is required for nuclear mRNA export through its interaction with Yralp. Nature 413: 648-652.

Strasser, K., Masuda, S., Mason, P., Pfannstiel, J., Oppizzi, M., Rodriguez-Navarro, S., Rondon, A.G., Aguilera, A., Struhl, K., Reed, R., et al. 2002. TREX is a conserved complex coupling transcription with messenger RNA export. Nature 417: 304-308.

Strome, S. and Wood, W.B. 1982. Immunofluorescence visualization of germ-line-specific cytoplasmic granules in embryos, larvae, and adults of Caenorhabditis elegans. Proc. Natl. Acad. Sci. 79: 15581562 .

Stutz, F., Bachi, A., Doerks, T., Braun, I.C., Seraphin, B., Wilm, M., Bork, P., and Izaurralde, E. 2000. REF, an evolutionary conserved family of hnRNP-like proteins, interacts with TAP/Mex67p and participates in mRNA nuclear export. RNA 6: 638-650.

Takagaki, Y. and Manley, J.L. 1997. RNA recognition by the human polyadenylation factor CstF. Mol. Cell. Biol. 17: 3907-3914.

. 2000. Complex protein interactions within the human polyadenylation machinery identify a novel component. Mol. Cell. Biol. 20: $1515-1525$

Tan, W., Zolotukhin, A.S., Bear, J., Patenaude, D.J., and Felber, B.K. 2000. The mRNA export in Caenorhabditis elegans is mediated by Ce-NXF-1, an ortholog of human TAP/NXF and Saccharomyces cerevisiae Mex67p. RNA 6: 1762-1772.

Tang, J. and Rosbash, M. 1996. Characterization of yeast U1 snRNP A protein: Identification of the N-terminal RNA binding domain (RBD) binding site and evidence that the C-terminal RBD functions in splicing. RNA 2: 1058-1070.

Urlaub, H., Hartmuth, K., Kostka, S., Grelle, G., and Luhrmann, R. 2000. A general approach for identification of RNA-protein crosslinking sites within native human spliceosomal small nuclear ribonucleoproteins (snRNPs). Analysis of RNA-protein contacts in native U1 and U4/U6 - U5 snRNPs. J. Biol. Chem. 275: 41458-41468.

Yi, W. and Zarkower, D. 1999. Similarity of DNA binding and transcriptional regulation by Caenorhabditis elegans MAB-3 and Drosophila melanogaster DSX suggests conservation of sex determining mechanisms. Development 126: 873-881.

Zahn, T.R., Macmorris, M.A., Dong, W., Day, R., and Hutton, J.C. 2001. IDA-1, a Caenorhabditis elegans homolog of the diabetic autoantigens IA-2 and phogrin, is expressed in peptidergic neurons in the worm. J. Comp. Neurol. 429: 127-143.

Zenklusen, D., Vinciguerra, P., Wyss, J.C., and Stutz, F. 2002. Stable $\mathrm{mRNP}$ formation and export require cotranscriptional recruitment of the mRNA export factors Yralp and Sub2p by Hpr1p. Mol. Cell. Biol. 22: 8241-8253.

Zhang, M. and Green, M.R. 2001. Identification and characterization of $y U A P / S u b 2 p$, a yeast homolog of the essential human premRNA splicing factor hUAP56. Genes \& Dev. 15: 30-35.

Zhang, W.J. and Wu, J.Y. 1996. Functional properties of p54, a novel SR protein active in constitutive and alternative splicing. Mol. Cell. Biol. 16: 5400-5408.

Zhou, Z., Luo, M.J., Straesser, K., Katahira, J., Hurt, E., and Reed, R. 2000. The protein Aly links pre-messenger-RNA splicing to nuclear export in metazoans. Nature 407: 401-405.

Zorio, D.A. and Blumenthal, T. 1999. Both subunits of U2AF recognize the $3^{\prime}$ splice site in Caenorhabditis elegans. Nature 402: 835838.

Zorio, D.A., Lea, K., and Blumenthal, T. 1997. Cloning of Caenorhabditis U2AF65: An alternatively spliced RNA containing a novel exon. Mol. Cell. Biol. 17: 946-953. 

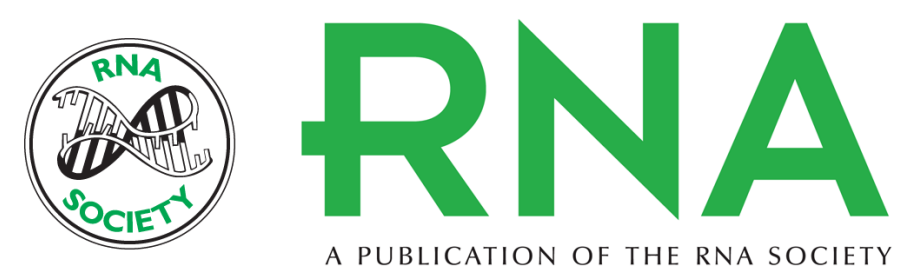

A PUBLICATION OF THE RNA SOCIETY

\section{UAP56 levels affect viability and mRNA export in Caenorhabditis elegans}

MARGARET MACMORRIS, CHAD BROCKER and THOMAS BLUMENTHAL

RNA 2003 9: 847-857

References This article cites 62 articles, 38 of which can be accessed free at:

http://rnajournal.cshlp.org/content/9/7/847.full.htmI\#ref-list-1

\section{License}

Email Alerting

Service

Receive free email alerts when new articles cite this article - sign up in the box at the top right corner of the article or click here. 